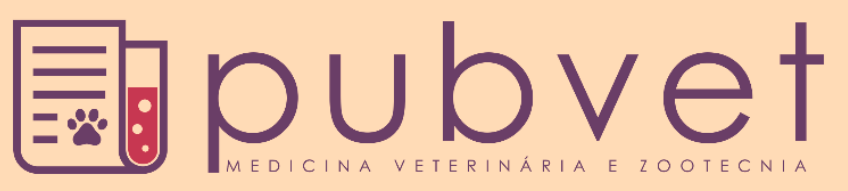

https://doi.org/10.31533/pubvet.v15n07a874.1-6

\title{
Hospital escola de grandes animais: Papel na vigilância de zoonoses de importância em saúde pública
}

\author{
Marcos Vinícius Nobre Leitão ${ }^{1 \bullet}$, Ligia Cantarino $2^{*} \bullet$ \\ ${ }^{1}$ Acadêmico de Medicina Veterinária. Faculdade de Agronomia e Medicina Veterinária, Universidade de Brasília-DF. \\ ${ }^{2}$ Docente - Faculdade de Agronomia e Medicina Veterinária, Universidade de Brasília-DF. \\ *Autor para correspondência, E-mail: ligiacantarino@unb.br
}

Resumo. O registro dos casos de enfermidades nos animais tem suas origens desde antigas civilizações. Existe uma preocupação em se relatar essas enfermidades tanto por conta do contato familiar e profissional dos homens com os animais, quanto pela biosseguridade que algumas espécies devem apresentar até serem consumidas. Os hospitais veterinários assumem papel importante como partícipes na estratégia de trabalho integrado na vigilância de zoonoses de importância em saúde pública. Apresentamos aqui um estudo direcionado no Distrito Federal, a partir do Hospital Veterinário (HVet) da Universidade de Brasília. O estudo descritivo, retrospectivo, foi realizado por meio de levantamento no livro de registro de animais atendidos no setor de grandes animais do HVet/UnB, localizado na Granja do Torto, de janeiro de 2015 a janeiro de 2020 (61 meses). Os casos foram ordenados segundo a espécie, sexo, ano e mês de entrada no hospital, origem dos animais segundo seus tutores ou apresentação e desfecho do caso. Foram registrados 2008 atendimentos no período. Foi identificado que $10 \%$ (203/2008) dos atendimentos foram de casos suspeitos ou diagnosticados de zoonoses e/ou com potencial zoonótico, distribuídos entre espécies equina (32\%), ovina (29\%), bovina (24\%), caprina (12\%), suína (2\%) e bubalina (1\%). Quanto à origem, 77\% dos casos foram de proprietários particulares, $8 \%$ de apreensão, $10 \%$ de origem da UnB (Fazenda Água Limpa-FAL e HVet) e 6\% de órgãos públicos como serviço de apreensão de animais da Secretaria e Agricultura. As doenças reprodutivas (distocias, parto distócico, prolapso vaginal/útero, aborto, retenção de placenta, placentite, vaginite, endometrite, metrite) representaram 34\% dos casos. As doenças neurológicas (meningoencefalite, raiva, encefalite viral, quadro neurológico, alteração em SNC, tétano e listeriose) $21 \%$. As doenças parasitárias $1 \%$. As doenças respiratórias (pneumonia, actinomicose e tuberculose) $16 \%$, mastites $14 \%$, digestivas $4 \%$. Linfadenites foram $5 \%$ e as enfermidades dermatológicas (sarnas, dermatofilose, dermatofitose) constituíram 5\% dos atendimentos. Dos casos de doenças zoonóticas e de potencial zoonótico, no ano de 2015 houve registro de 38 casos (18,7\%), em 2016 foram 40 (19,7\%), em 2017, 31 (15,3\%), 2018 com 48 (23,6\%) em 2019 foram 44 (21,7\%) e em janeiro de 2020, 2 casos (1\%).

Palavras-chave: Hospital veterinário, saúde única, vigilância epidemiológica, zoonoses

\section{Large animal teaching hospital: Role in the surveillance of zoonoses of public health importance}

Abstract. The record of disease cases in animals has its origins in ancient civilizations.
There is a concern in reporting these diseases both because of the family and professional
contact between men and animals, and because of the biosafety that some species must
present until they are consumed. Veterinary hospitals play an important role as participants
in the integrated work strategy in the surveillance of zoonoses of public health importance.
We present here a study directed at the Federal District, from the Veterinary Hospital 
(HVet) of the University of Brasília. The descriptive, retrospective study was carried out through a survey in the registration book of animals assisted in the large animals sector of HVet/UnB, located in Granja do Torto, from January 2015 to January 2020 (61 months). The cases were sorted according to species, sex, year and month of admission to the hospital, origin of the animals according to their guardians, or presentation and outcome of the case. 2008 services were registered in the period. It was identified that 10\% (203/2008) of the consultations were suspected or diagnosed cases of zoonoses and/or with zoonotic potential, distributed among equine (32\%), sheep (29\%), bovine (24\%), and goat species $(12 \%)$, swine (2\%) and buffalo (1\%). As for the origin, $77 \%$ of the cases were from private owners, $8 \%$ from apprehension, 10\% from UnB (Fazenda Água Limpa-FAL and HVet) and $6 \%$ from public agencies as a service for apprehension of animals from the Secretariat and Agriculture. Reproductive diseases (dystocia, dystocia, vaginal/uterine prolapse, abortion, retained placenta, placentates, vaginitis, endometritis, metritis) accounted for $34 \%$ of cases. Neurological diseases (meningoencephalitis, rabies, viral encephalitis, neurological symptoms, CNS disorders, tetanus and listeriosis) $21 \%$. Parasitic diseases $1 \%$. Respiratory diseases (pneumonia, actinomycosis and tuberculosis) 16\%, mastitis 14\%, digestive 4\%. Lymphadenitis was $5 \%$ and dermatological diseases (scabies, dermatophilosis, dermatophytosis) constituted $5 \%$ of the visits. Of the cases of zoonotic diseases and zoonotic potential, in 2015 there were 38 cases (18.7\%), in 2016 there were $40(19.7 \%)$, in $2017,31(15.3 \%), 2018$ with $48(23.6 \%)$ in 2019 were $44(21.7 \%)$ and in January 2020, 2 cases (1\%).

Keywords: Veterinary hospital, one health, epidemiological surveillance, zoonoses

\section{Introdução}

Em diferentes civilizações e em variados tempos históricos adveio o interesse humano em registrar casos de enfermidades de animais. Mudanças climáticas, globalização e intensificação da produção animal contribuem para a emergência e reemergência de doenças (Tavares et al., 2018; Zanella, 2016). As alterações na forma de produção dos animais domésticos, seja diante tanto da necessidade de consumo alimentar quanto em serventia militar, podem acarretar mudanças no perfil dos problemas sanitários intrínsecos ao convívio. O aprimoramento das formas de registro das observações da ocorrência de doenças fornece informações que, traduzidas em políticas de higiene, manejo e abate animal, contribuem para melhorar aspectos sociais essenciais ao longo do tempo (Pfuetzenreiter et al., 2004). A efetividade em buscar de forma precisa, na sociedade, a relevância da reação a determinada doença, foi que deu origem a uma das formas primordiais de se realizar a saúde pública, hoje conhecida como medicina veterinária preventiva (Martínez-López et al., 2009).

As doenças, em geral, são definidas como a variação do estado homeostático das funções corpóreas e podem ocorrer por diversos motivos, sendo fator de importância para a variação fisiológica aquelas causadas por agentes patogênicos. Estes podem agir de forma ativa ou por meio da liberação de suas toxinas, podem advir não somente de reservatórios na forma de seres vivos, mas também do meio ambiente (Woolhouse \& Gowtage-Sequeria, 2005). Há ainda o caso de alguns parasitas que são indesejados pela infestação de um hospedeiro por conta do consumo de seus recursos vitais e, por vezes, mais difíceis de tratar por inocularem outros seres patogênicos durante o processo de alimentar-se (Monteiro, 2011).

Em 1951, o termo saúde pública veterinária foi estabelecido pela Organização Mundial de Saúde (OMS) como as medidas de Medicina Veterinária para prevenção, proteção da vida, e promoção do bem-estar e eficiência do ser humano. Desse modo, os hospitais veterinários podem ser considerados como peça fundamental nesse contexto, pois diversas relações dinâmicas entre o agente etiológico, o hospedeiro e o meio ambiente são, por sua gravidade, levados para análise clínica individual (Brasil, 2016). Dessa maneira, a terminologia da Saúde Única, em que a saúde dos animais e dos homens e do meio ambiente são tratados como igualmente relevantes, se apresenta da sua maneira mais plena quando o tema a ser tratado é com relação àquelas doenças que podem ser transmitidas entre humanos e animais, as chamadas zoonoses (Osburn et al., 2009; Tavares et al., 2018; Zanella, 2016). 
As zoonoses representam 75\% das doenças reemergentes em humanos (Santos et al., 2011; $\underline{\text { Vale et }}$ al., 2009). Os médicos veterinários, em razão dos trabalhos médicos e epidemiológicos que prestam, são os que mais têm contato com esse risco, da mesma forma que são os responsáveis por apresentar medidas para se evitar essas situações e, antes disso, vigiar as suas ocorrências a partir da sua localidade. Desta forma, Hospitais Veterinários assumem papel importante como partícipes na estratégia de trabalho integrado na vigilância de zoonoses de importância em saúde pública (Osburn et al., 2009; Tavares et al., 2018; Zanella, 2016).

Apresentamos, aqui, um estudo direcionado ao Distrito Federal (DF), a partir do setor de grandes animais do Hospital Veterinário da Universidade de Brasília (UnB), acerca das zoonoses e potenciais zoonoses atendidas na rotina clínica.

O objetivo do trabalho foi descrever número de casos clínicos de doenças comprovadamente zoonóticas ou potencialmente zoonóticas registradas no setor de grandes animais do Hospital Veterinário da UnB de janeiro de 2015 a janeiro de 2020.

\section{Metodologia}

O estudo descritivo, retrospectivo, foi realizado por meio de levantamento no livro de registro de animais atendidos no setor de grandes animais do Hospital Veterinário da UnB, localizado na Granja do Torto, Brasília-DF de janeiro de 2015 a janeiro de 2020 (61 meses). Os casos foram ordenados segundo a espécie, sexo, ano e mês de entrada no hospital, origem dos animais segundo seus tutores ou apresentação, e desfecho do caso. Quanto às manifestações clínicas, havia, no registro, anotações das ocorrências nesses cinco anos e, dentre essas, destacou-se as que apresentam potencial zoonótico. Para as análises descritivas foi utilizado o software Microsoft Excel $^{\circledR} 2010$.

\section{Resultados e discussão}

Foram registrados 2008 atendimentos no período estudado. A Tabela 1 apresenta a distribuição dos atendimentos por espécie animal.

Tabela 1. Número de animais atendidos no HVet/UnB distribuídos por espécie de janeiro de 2015 a janeiro de 2020

\begin{tabular}{lccccccc}
\hline \multirow{2}{*}{ Ano } & \multicolumn{7}{c}{ Espécie Animal (N) } \\
\cline { 2 - 8 } & Equina & Bovina & Ovina & Caprina & Suína & Outra & Total \\
\hline 2015 & 236 & 77 & 77 & 17 & 17 & 8 & 432 \\
2016 & 185 & 70 & 41 & 17 & 43 & 4 & 361 \\
2017 & 209 & 65 & 50 & 22 & 24 & 19 & 389 \\
2018 & 219 & 49 & 104 & 14 & 11 & 6 & 403 \\
2019 & 239 & 56 & 82 & 14 & 7 & 2 & 400 \\
2020 & 17 & 1 & 2 & 3 & - & - & 23 \\
\hline Total $(\%)$ & $1105(55,0 \%)$ & $318(15,8 \%)$ & $356(17,7 \%)$ & $87(4,3 \%)$ & $102(5 \%)$ & $40(2 \%)$ & $2008(100 \%)$ \\
\hline
\end{tabular}

Quanto à origem dos animais atendidos, $77 \%$ dos casos foram de proprietários particulares, $8 \%$ do serviço de apreensão de animais da Secretaria e Agricultura do DF, $10 \%$ de origem da própria UnB (Fazenda Água Limpa-FAL e HVet) e 6\% oriundos de outros órgãos públicos (Ex. Embrapa, Emater, Exército).

Foi identificado que 10\% (203/2008) dos atendimentos foram de casos suspeitos ou diagnosticados de zoonoses e/ou com potencial transmissão zoonótica, distribuídos entre espécies equina (32\%), ovina (29\%), bovina (24\%), caprina (12\%), suína (2\%) e bubalina (1\%) (Gráficos 1 e 2).

Em estudo semelhante realizado no mesmo hospital, os autores verificaram que 18,9\% dos atendimentos eram de doenças zoonóticas ou com de potencial zoonótico (Borges \& Cantarino, 2012).

As enfermidades parasitárias contabilizaram 1\%; as doenças respiratórias (pneumonia, actinomicose e tuberculose) 16\%; mastites 14\%, as digestivas (diarreias) $4 \%$. Linfadenites foram $5 \%$ e as enfermidades dermatológicas (sarnas, dermatofilose, dermatofitose) constituíram 5\% dos atendimentos.

Dos casos de doenças zoonóticas e de potencial transmissão zoonótica, no ano de 2015 houve registro de 38 casos (18,7\%), em 2016 foram 40 (19,7\%), em 2017, 31 (15,3\%), em 201848 (23,6\%), em 2019 $44(21,7 \%)$ e em janeiro de 2020, 2 casos (1\%) (Tabela 2). 
Tabela 2. Atendimentos com potencial transmissão zoonótica no HVet/UnB de 2015 a 2020.

\begin{tabular}{lcc}
\hline Alterações/Patologia & $\mathrm{N}^{\mathrm{o}}$ de Atendimentos & $\%$ \\
\hline $\begin{array}{l}\text { Alterações reprodutivas (distocias, parto distócico, prolapso vaginal/útero, aborto, } \\
\text { retenção de placenta, placentite, vaginite, endometrite, metrite) }\end{array}$ & 68 & $34 \%$ \\
$\begin{array}{l}\text { Alterações neurológicas (meningoencefalite, raiva, encefalite viral, quadro neurológico, } \\
\text { alteração em SNC, tétano, listeriose) }\end{array}$ & 43 & $21 \%$ \\
\hline $\begin{array}{l}\text { Alterações Dermatológicas (dermatofitose, dermatofilose, ptiose, sarna, actinomicose) } \\
\text { Alterações respiratórias (pneumonia, broncopneumonia, pleuropneumonia, } \\
\text { rhodococose, tuberculose) }\end{array}$ & 11 & $5 \%$ \\
\hline Alterações digestivas (colibacilose, diarreias, enterite, enterotoxemia) & 32 & $16 \%$ \\
\hline Patologias Parasitárias (toxoplasmose) & 8 & $4 \%$ \\
Patologias linfáticas (linfadenite, linfadenite caseosa) & 2 & $1 \%$ \\
\hline Mastites & 11 & $5 \%$ \\
\hline Total & 28 & $14 \%$ \\
\hline Obs. Número total de animais atendidos no período, $\mathrm{N}=2008$ & 203 & $100 \%$ \\
\hline
\end{tabular}

Os casos foram distribuídos com proporções semelhantes entre os anos analisados (Gráfico 1). Em relação à distribuição desses casos entre as espécies, os equinos representam a maioria dos casos com $32 \%$, seguidos dos casos de ovinos com 29\% e bovinos com $24 \%$ (Gráficos 1 e 2).

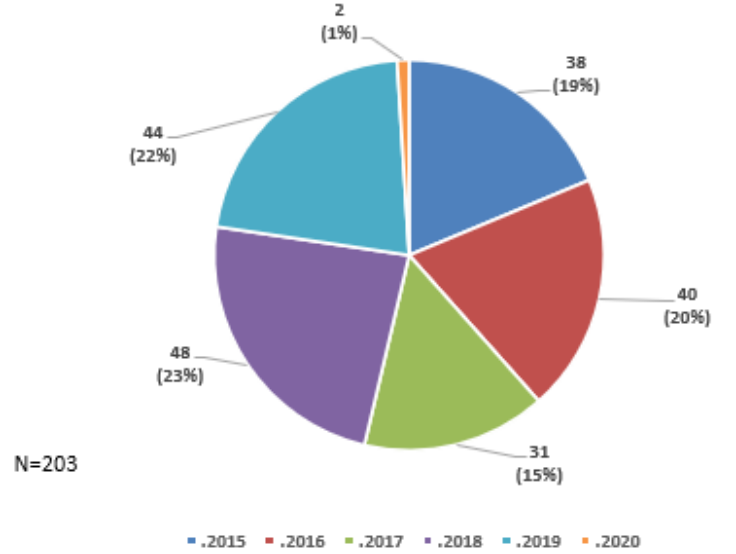

Gráfico 1. Distribuição dos atendimentos do HVet/UnB registrados como doença zoonótica ou com potencial zoonótico por ano, de 2015 a 2020.

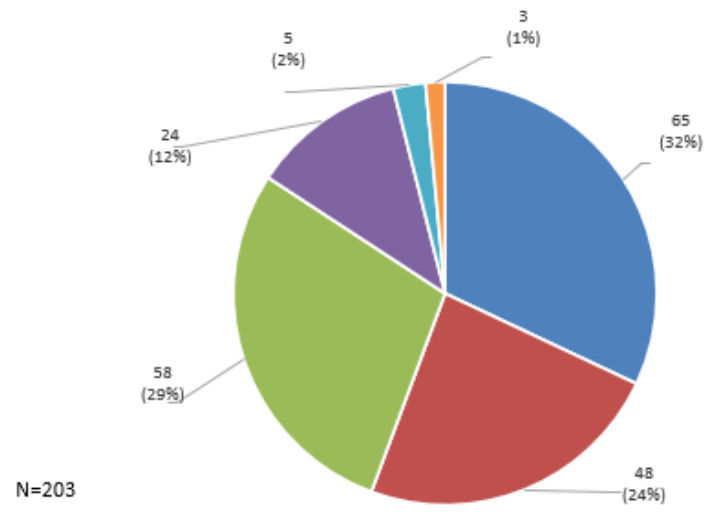

- equina = bovina - ovina - caprina = suina - bubalina

Gráfico 2. Distribuição dos atendimentos do HVet/UnB registrados como doença zoonótica ou com potencial transmissão zoonótica, por espécie animal, de 2015 a 2020.

As doenças reprodutivas (distocias, parto distócico, prolapso vaginal/útero, aborto, retenção de placenta, placentite, vaginite, endometrite e metrite) representaram $34 \%$ dos casos. Podem ser consideradas como doenças ou alterações potencialmente zoonóticas as doenças da esfera reprodutiva como, por exemplo, distocias, prolapsos de vagina ou útero, retenção de envoltórios fetais e abortos. Esses sinais clínicos podem ser secundários para importantes zoonoses como a brucelose, leptospirose, toxoplasmose, infecções por clamídia (esta última principalmente em pequenos ruminantes). Pneumonias sem causa específica também podem ser zoonóticas. Agentes que afetam o homem como salmonela, pasteurela e microbactérias podem ser responsáveis pelo desenvolvimento dessa doença nos ruminantes. Mastite e diarreias podem ser causadas por microrganismos que que também causam danos à saúde humana, como a mastite desenvolvida por S. aureus e as diarreias por E. coli e Salmonela spp (Borges et al., 2008; Zanella, 2016).

As alterações neurológicas (meningoencefalite, raiva, encefalite viral, quadro neurológico, alteração em SNC, tétano, listeriose) foram da ordem de 21\%. Estudo de Novais (2013) apontou que entre 2001 a 2012, foram atendidos no HVet/UnB, 37 ovinos e 14 caprinos com sinais neurológicos. Segundo Feldman (1997), as neuropatias tem um papel importante entre as doenças que acometem os ruminantes, sendo muitas delas zoonoses, podendo apresentar alta morbidade e letalidade, com perdas econômicas expressivas.

Outro aspecto que deve ser ressaltar é o registro de casos de raiva no HVet/UnB. Foram verificados, neste levantamento, casos de raiva em herbívoros: 6 em equinos, 6 em bovinos, em ovinos e caprinos 
houve o registro de 1 caso de cada espécie. Os anos de 2015 e 2018 foram apresentaram 4 e 5 suspeitas respectivamente, em 2016 e 2019 tiveram 2 casos em cada ano e, 2017 contou com 1 caso suspeito.

De 2001 a 2005 foram atendidos no HVet/UnB cerca de 1.280 ruminantes, e foram registrados 30 casos de raiva atendidos em ruminantes: 28 casos foram em bovinos, 1 caso em ovino e 1 em bubalino sendo que, em 2003, ocorreu como surto de raiva em herbívora no DF (Araújo, 2005). Em estudo com pequenos ruminantes, no período de 2001 a 2012, houve a confirmação diagnóstica de 1 caso em ovino (Novais, 2013).

As doenças neurológicas apresentaram elevado número de casos e, como a muitas apresentam sinais e sintomas semelhantes, cuidados devem ser adotados no manejo dos animais, principalmente diante da possibilidade de ser um caso de raiva, conforme ressaltado por Borges et al. (2008) e Holanda (2016), sobre a necessidade de implementar normas e protocolos de biossegurança na rotina de atendimento em ambiente hospitalar veterinário.

\section{Considerações finais}

Foram registrados atendimentos de animais com sinais clínicos e ou com suspeitas clínicas de algumas doenças potencialmente zoonóticas, sem, no entanto, ter o diagnóstico fechado ou conclusivo. A depender do microrganismo envolvido, poderiam ser consideradas de risco para a saúde humana, cabendo aqui o reforço da importância em fechar o diagnóstico com investimento na capacidade laboratorial.

O conhecimento das principais enfermidades da região de abrangência do hospital pode contribuir com o estabelecimento de medidas de controle e profilaxia na região. $\mathrm{O}$ monitoramento e análise da distribuição dos casos de doenças zoonóticas e com potencial zoonóticos registradas no HVet/UnB se mostra importante seja pela ampliação das práticas extensionistas como as de educação sanitária e de pesquisa, seja como contribuição para implementação de medidas de controle sanitário, dada a relevância no aspecto de saúde pública do Distrito Federal.

Com o atual contexto demográfico e de globalização, percebemos um vírus, provavelmente zoonótico, que causa a Covid-19, sendo abordado pelas mais diversas profissões da saúde, inclusive a Medicina Veterinária, constituindo e reafirmando o conceito de Saúde Única, em que a saúde dos animais, dos homens e do ambiente são tratadas como igualmente relevantes.

\section{Referências}

Araújo, V. G. (2005). Zoonoses em ruminantes atendidos pelo Hospital Escola de Grandes Animais da UnB/SEAPA, janeiro de 2001 a julho de 2005. Trabalho de conclusão de curso. (Graduação em Medicina Veterinária). Universidade de Brasília.

Borges, G. B. O.; Cantarino, L. (2012). Zoonoses e doenças com potencial zoonótico identificadas

Hospital Escola de Grandes Animais da Granja do Torto da Universidade de Brasília. Relatório final

- Programa de Iniciação Científica. Universidade de Brasília.

Borges, J. R. J., Godoy, R. F., Raphael, A., Neto, T., Costa, L. M. C. (2008). Biossegurança na experimentação e na clínica veterinária: Biossegurança na clínica de grandes animais. Ciências Veterinárias nos Trópicos, 11 (Supl. 1), 158-162.http://www.rcvt.org.br/suplemento11/159-162.pdf.

Brasil. Ministério da Saúde. Manual de vigilância, prevenção e controle de zoonoses. Brasília: Ministério da Saúde, 2016. http://www.rcvt.org.br/suplemento11/159-162.pdf.

Holanda, C. A. (2016). Considerações gerais sobre o gerenciamento de resíduos de serviços de saúde e prevenção de riscos ambientais do hospital veterinário de grandes animais da Universidade de Brasília (p. 57 p.). Trabalho de conclusão de curso. (Graduação em Medicina Veterinária). Universidade de Brasília. https://www.bdm.unb.br/handle/10483/16248.

Martínez-López, B., Perez, A. M., Sánchez-Vizcaíno, J. M. (2009). Social network analysis. Review of general concepts and use in preventive veterinary medicine. Transboundary and Emerging Diseases, 56(4), 109-120. https://doi.org/10.1111/j.1865-1682.2009.01073.x .

Monteiro, S. G. (2011). Parasitologia na Medicina Veterinária (Vol. 1). São Paulo: Editora Roca Ltda. Novais, E. P. F. (2013). Doenças com sinais neurológicos em ovinos e caprinos no Distrito Federal e 
entorno. Dissertação. (Mestrado em Saúde Animal). Universidade de Brasília, https://repositorio.unb.br/bitstream/10482/14331/1/2013_ErnanePaivaFerreiraNovais.pdf.

Osburn, B., Scott, C., Gibbs, P. (2009). One world —one medicine - one health: emerging veterinary challenges and opportunities. Revue Scientifique et Technique, 28(2), 481-486. https://doi.org/10.20506/rst.28.2.1884.

Pfuetzenreiter, M. R., Zylbersztajn, A., Ávila-Pires, F. D. de. (2004). Evolução histórica da medicina veterinária preventiva e saúde pública. Ciência Rural, 34(5), 1661-1668. https://doi.org/10.1590/s0103-84782004000500055.

Santos, P. M., Voltolini, T. V., Cavalcante, A. C. R., Pezzopane, J. R. M., Moura, M. S. B., Silva, T. G. F., Bettiol, G. M. (2011). Mudanças climáticas globais e a pecuária: cenários futuros para o Semiárido brasileiro. Revista Brasileira de Geografia Física, 4(6), 1176-1196. https://periodicos.ufpe.br/revistas/rbgfe/article/view/232765/26767.

Tavares, G. C., Leibowitz, M. P., Leal, C. A. G., Figueiredo, H. C. P. (2018). Zoonoses emergentes associadas ao consumo e à manipulação de pescado. Cadernos Técnicos da Escola de Veterinária da UFMG, 89, 7-38. https://vet.ufmg.br/ARQUIVOS/FCK/file/cteletronico\%2089\%20(1).pdf

Vale, M. M., Alves, M. A. S., Lorini, M. L. (2009). Mudanças climáticas: desafios e oportunidades para a conservação da biodiversidade brasileira. Oecologia Brasiliensis, 13(3), 518-535. https://doi.org/10.4257/oeco.2009.1303.07.

Woolhouse, M. E. J., Gowtage-Sequeria, S. (2005). Host range and emerging and reemerging pathogens. Emerging Infectious Diseases, 11(12), 1842-1847. https://doi.org/10.3201/eid1112.050997.

Zanella, J. R. C. (2016). Zoonoses emergentes e reemergentes e sua importância para saúde e produção animal. Pesquisa Agropecuária Brasileira, 51(5), 510-519. https://doi.org/10.1590/S0100204X20160005000011.

Histórico do artigo:

Recebido: 27 de janeiro de 2021

Aprovado: 23 de março de 2021
Licenciamento: Este artigoé publicado na modalidade Acesso Aberto sob a licença Creative Commons Atribuição 4.0 (CC-BY 4.0), a qual permite uso irrestrito, distribuição, reprodução em qualquer meio, desde que o autor e a fonte sejam devidamente creditados. 